BULLETIN Bulletin hispanique

HISPANIQUE Université Michel de Montaigne Bordeaux

$114-2 \mid 2012$

Varia

\title{
El español de los negocios en el siglo XIX
}

la Nueva correspondencia comercial francesa-española de José M. Lopes (París, Truchy, 1864)

\section{Ángeles García Aranda}

\section{OpenEdition}

1 Journals

Edición electrónica

URL: https://journals.openedition.org/bulletinhispanique/2223

DOI: 10.4000/bulletinhispanique.2223

ISSN: 1775-3821

Editor

Presses universitaires de Bordeaux

Edición impresa

Fecha de publicación: 31 diciembre 2012

Paginación: 853-872

ISBN: 978-2-86781-855-4

ISSN: 0007-4640

Referencia electrónica

Ángeles García Aranda, «El español de los negocios en el siglo XIX», Bulletin hispanique [En línea],

114-2 | 2012, Publicado el 05 enero 2016, consultado el 29 julio 2022. URL: http://

journals.openedition.org/bulletinhispanique/2223 ; DOI: https://doi.org/10.4000/bulletinhispanique. 2223

All rights reserved 


\title{
El español de los negocios en el siglo XIX: la Nueva correspondencia comercial francesa-española de José M. Lopes (París, Truchy, 1864)
}

\author{
Ángeles García Aranda \\ Universidad Complutense de Madrid
}

En 1864, est publiée à Paris la Nueva correspondencia comercial de José. M. Lopes, ouvrage bilingue français-espagnol qui contient les éléments essentiels de la langue des affaires. L'article analyse la langue des écrits commerciaux ainsi que les répertoires lexicaux pour montrer l'importance et l'intérêt de ce type d'ouvres, ni littéraires ni lingüistiques, dans l'histoire de la langue espagnole ainsi que pour l'enseignement de l'espagnol deuxième langue.

Mots-clés : Lexicographie, langue française, l'espagnol des affaires.

En 1864, se publica en París la Nueva correspondencia comercial de José M. Lopes, obra bilingüe francés-español que recoge los fundamentos del lenguaje de los negocios. Este trabajo analiza con detalle la lengua empleada tanto en los escritos comerciales como en los repertorios léxicos para demostrar la importancia y el interés de estas obras, ni literarias ni lingüisticas, en la historia de la lengua española, asi como en la enseñanza del español como segunda lengua.

Palabras clave: Lexicografía, lengua francesa, español de los negocios.

In 1864, the "Nueva Correspondencia Comercial” by Jose M. Lopes, was published in Paris. It was a bilingual, French-Spanish book, containing the main features of the business language. The prensent article will analyse the language of commercial writings, as the lexical index, to show how important and interresting that type of work is, neither literary nor linguisitc, in the history of the Spanish language, as for the teaching of Spanish as second language.

Key words: lexicography, french language, spanish of the business. 


\section{INTRODUCCIÓN}

Durante el siglo XIX se produjo un aumento considerable de las transacciones económicas tanto entre los países europeos como entre el Viejo Continente y América. La Revolución Industrial, el crecimiento de los mercados, las invenciones científio-técnicas y su aplicación a la industria, el auge del ferrocarril y de la navegación a vapor o el desarrollo de la Banca hicieron posible un comercio activo y próspero que tuvo notables consecuencias lingüísticas. En esta centuria, y como consecuencia de las nuevas políticas económicas, se publicaron numerosos tratados bilingües sobre el lenguaje comercial ${ }^{1}$, especialmente sobre su léxico, pues, como señala el editor en la introducción a la Nueva correspondencia comercial francesa-española (p. 5), "con el conocimiento de las lenguas extrangeras, podrá corresponder un comerciante, en su lengua natal, con sus comitentes extrangeros, y estos, a su vez, le contestarán en su propio idioma, entendiéndose así todos recíprocamente sin necesidad de terceros».

La importancia que adquiere el léxico del comercio en estos momentos determina el análisis de la Nueva correspondencia comercial francesa-español, que contiene la definición y explicación del lenguage comercial y económico [...] de José M. Lopes (París, J. H. Truchy, 1864), obra que incluye un vocabulario comercial bilingüe francés-español, una nomenclatura, también bilingüe, de «los términos de comercio, banco y contabilidad», y una lista de mercancías. Este trabajo, por tanto, analiza el español escrito de los negocios en el siglo XIX, así como el tratamiento del léxico de especialidad y su presencia en el Diccionario de la Academia, pues la aparición de obras científicas y técnicas y las traducciones de textos especializados ocasionó la inclusión de abundantes tecnicismos en los diccionarios generales.

\section{LA NUEVA CORRESPONDENCIA.}

ESTRUCTURA, CONTENIDO Y OBJETIVOS

La Nueva correspondencia comercial francesa-española que contiene la definición y explicación del lenguage comercial y económico; numerosos modelos de cartas,

1. En esta centuria también se publicaron tratados monolingües sobre el lenguaje comercial en la mayoría de las lenguas europeas importantes, como A commercial dictionary: containing the present state of mercantile law, practice and custom de J. Montefiore (1804), Crosby's merchant's and tradesman's pocket dictionary, adapted to merchants, manufacturers, and traders in all the various branches of commercial intercourse de B. Crosby (1808), A General Dictionary of Commerce, Trade and Manufactures de T. Mortimer (1810), Diccionario de hacienda, con aplicación a España de J. Canga Argüelles (1833), Enciclopedia del negoziante de Antonelli (1839), UniversalLexikon für kaufleute und Fabrikanten, oder, Vollständiges Handbuch des Handels-, Fabrik- und Manufakturwesens de J. R. McCulloch (1842), Diccionario universal del comercio, de la banca, de las manufacturas y de las mercaderias de Martínez-Aguilar (1845), Neuestes Universal-Lexicon der gesammten Kaufmännischen Wissenschaften Untertitel für Kaufleute, Fabrikanten u. überhaupt jeden Geschäftsmann de L. Fort (1852), Otto Spamer's illustriertes Handels-Lexikon: praktisches Hülfs- und Nachschlagebuch über alle Gegenstände und Verhältnisse des Handels und Weltverkehrs de O. Spamer (1876)... 
circulares, ofrecimientos de servicio, entrada en relaciones, operaciones comerciales, informes, reclamaciones, remisas de dinero, cuentas corrientes, etc., cartas de crédito, modelos varios y fórmulas, facturas, escrituras privadas, poderes, etc., pagarés, letras de cambio; una nomenclatura de los términos de comercio, banco y contabilidad en francés-español y en español-francés, cuadros comparativos de las monedas de España, Francia, Inglaterra, etc., pesos, medidas y sistema métrico; una lista de mercancías y los principales artículos del Código de Comercio es un tratado bilingüe -en las páginas pares el francés y en las impares el espańol- que se compuso, como se afirma en la introducción, para proporcionar "gran auxilio a los comerciantes de Francia y España en sus operaciones internacionales».

La obra la firma José M. Lopes, «autor de varias obras para el estudio de la lengua española» ${ }^{3}$, si bien la mandó componer y la costeó J. H. Truchy, editor "penetrado de la utilidad de las lenguas extrangeras, hace treinta años que me estoy consagrando a su propagación y el catálogo de mi casa puede atestiguar los esfuerzos que he hecho para alcanzar este resultado. En él se hallan numerosas obras metódicas para aprender el inglés, alemán, italiano y español» (Introducción, p. 7).

La Nueva correspondencia se estructura en varias partes:

- 1) Un lenguaje comercial y económico explicado (p. 22-107), esto es, un vocabulario de términos de especialidad para los comerciantes que «necesitan tener conocimientos especiales que no debe ignorar so pena de perjudicar a sus intereses».

- 2) Una correspondencia comercial, o modelos de cartas y documentos muy útiles para el desempeño de la labor de comerciante, banquero, fabricante o comisionista (p. 112-451). Es la parte más importante de toda la obra e incluye más de ciento veinte escritos que se utilizaban para diversos fines, por lo que los divide en circulares (sobre la fundación de una casa de comercio, anunciando un nuevo socio, el retiro de un socio, la mudanza de casa, un depósito de vinos y frutos, la salida de vapores o una quiebra, dando aviso de expedición o la contestación a una carta de difuntos), ofrecimientos de servicio (para una casa de comisión, solicitando entrar en relaciones, proponiendo los productos de un país, con depósito de fondos, etc.), entrada en relaciones (contestación a un primer pedido, acusando recibo de un primer pedido o pedido a consecuencia de la visita de un socio), operaciones comerciales

2. La portada en francés es la siguiente:

Nouvelle correspondance commerciale française-espagnole contenant la définition et l'explication du langage commercial et économique; de nombreux modèles de lettres, circulaires, offres de service, entrée en relations, opérations commerciales, renseignements, réclamations, envois d'argent, comptes courants, etc., lettres de crédit, modèles divers et formules, factures, actes sous seing privé, procurations, etc., billets à ordre, lettres de change; une nomenclature des termes de commerce, banque, comptabilité, français-espagnol et espagnol-français, des tableaux comparatifs des monnaies d'Espagne, de France, d'Angleterre, etc., les poids, mesures, système métrique, une liste des marchandises et les principaux articles du Code de Commerce.

3. José M. Lopes es autor además de una Nouvelle grammaire pratique et raisonnée de la langue espagnole, París, Truchy / Goupy et Jourdan / Le Roy, 1866 (reeditada en 1885, 1901), de El español tal como se habla o Colección de conversaciones francesas y españolas, París, Truchy, 1867 (reeditada en 1879, 1883, 1889, 1893), de una Nouvelle méthode pratique de la langue espagnole, París, Le Roy, 1873 (vuelta a imprimir en 1882) y de una Novísima gramática de la lengua castellana, París, Delagrave / Bregi, 1882 (vuelta a imprimir en 1891), así como de las «notas sobre la gramática y los idiotismos» que se añaden a la edición parisina de 1867 de El sí de las niñas. 
(pedidos, compras y ventas, consignaciones, expediciones, reconvenciones, justificación, aceptación de letras o libranzas...), remesas de dinero (pagos, pedidos de dinero, remesas de valores y cuenta de resaca), quejas, respuestas (con motivo de una quiebra, remitiendo un mal crédito o anunciando un naufragio) y cuentas corrientes y de intereses (carta de crédito, carta de recomendación, carta de porte, cuenta de resaca, factura, escritura privada o poder general).

El editor de la Nueva correspondencia explica que la obra se ha estructurado a partir del orden natural adoptado en todas las casas de comercio

En efecto, ¿qué es lo que hace, en este ramo, un establecimiento cualquiera que acaba de fundarse? Empieza por darse a conocer por medio de circulares o avisos generales; luego dirige ofrecimientos de servicios o avisos particulares a las personas con quienes quiere entrar en relaciones. Entran después las proposiciones, los primeros negocios u operaciones, los pedidos, las órdenes, los pagos y, en una palabra, ese gran movimiento en la correspondencia, que trata de toda clase de negocios comerciales (p. 9).

- 3) Una «Nomenclature des termes de banque, commerce et comptabilité» (p. 453-480) francés-español y una «nomenclatura de los términos de banco, comercio y contabilidad» español-francés (p. 481-511) que recogen el vocabulario esencial del comercio, y de las que me ocuparé en las páginas siguientes.

- 4) Tres cuadros que compendian, respectivamente, las «monnaies espagnoles et leur réduction en monnaies françaises» (p. 513-514), las «monnaies françaises et leur réduction en monnaies espagnoles" (p. 515) y las "monnaies de différents pays réduites en monnaies françaises et espagnoles» (p. 516-525). Además, el autor proporciona una serie de consejos e informaciones sobre estas monedas, sus fracciones y sus correspondencias en otros países.

- 5) Un resumen del sistema decimal, los pesos y las medidas españolas con su correspondencia francesa (p. 526-533), en donde se recogen las equivalencias de legua, braza, vara, pie, dracma, escrúpulo, grano, cántaro, azumbre, cuartillo, aranzada, estadal, celemín, fanega, arroba, quintal, libra, onza o arroba.

- 6) Un «Dictionnaire des marchandises français-espagnol» (p. 534-567) y un «Diccionario de mercancías espańol-francés» (p. 568-604), que no es sino una amplia lista de productos y voces relacionadas con el comercio (abanicos, alabastro, aletas de ballena, argollas, azulejos, bismuto, bulto, cabestante, cachemir, canela de China, conservas, etiquetas, felpilla, maná, marroqui, merluza, mosquitero, muselina, obleas, pasamanería, percalina, pólvora, serrucho, sosa, tenacillas, toallas, vainilla, vitriolo, yunque...).

- 7) Los principales artículos del Código de Comercio francés traducidos al español (p. 606619), pues «ignorando los cambios y modificaciones del futuro Código [español], nos expondríamos a hacer incurrir en error a nuestro lectores, si copiásemos los artículos del Código actual; así pues, no insertaremos aquí ninguna de las leyes que rigen el comercio en España, puesto que van a ser próximamente modificadas».

Se trata, pues, de un compendio que recoge las principales nociones del lenguaje de correspondencia de los negocios, a saber, modelos de los escritos más habituales y un repertorio de las voces básicas, pues el comerciante debe tener conocimiento de los rasgos y usos lingüísticos que caracterizan esta variedad especializada si quiere desenvolverse con soltura y eficacia. La Nueva correspondencia, por tanto, se compone para completar la formación de los hombres de negocios de la época, y forma parte de la nómina de manuales comerciales que, dada la importancia de la materia, se utilizaban en numerosos centros de enseñanza 
Si el comercio exige la educación primaria y literaria que forma hoy día la base de todas las profesiones liberales, la clase de negocios que le caracteriza pide también conocimientos especiales y un estilo particular que en vano se buscaría en otra parte. Esto es lo que ha comprendido nuestra época, no tan solo honrando la carrera mercantil, sino perfeccionando también su enseńanza. En todos los establecimientos de educación secundaria bien dirigidos, se profesan los estudios comerciales con el mismo esmero que los clásicos. Hay hasta establecimientos consagrados exclusivamente a este género de enseñanza, donde se instruye a los jóvenes desde la gramática, escritura, aritmética, geografía y contabilidad, hasta los cursos de derecho comercial y marítimo, economía industrial y todos cuantos conocimientos son necesarios para formar contadores, banqueros, comerciantes, administradores, etc. (Introducción, p. 3 y 5)

La Nueva correspondencia, además, está redactada en dos lenguas, es decir, responde perfectamente a las necesidades lingüísticas del siglo XIX, centuria en la que las relaciones comerciales con el exterior eran trascendentales. El editor reconoce en las páginas preliminares que las lenguas más importantes en el comercio son el inglés, el francés y el español, ya que las naciones que las hablan son auténticas potencias en exportación de productos ${ }^{4}$. Su conocimiento permitirá, según Truchy (Introducción, p. 5), «completar la fusión de todos los pueblos, tan felizmente inaugurada con la navegación de vapor, los caminos de hierro, la electricidad y la uniformidad de monedas, pesos y medidas».

\section{El LENGUAJE COMERCiAL}

\section{Rasgos lingüísticos del español comercial}

El lenguaje escrito de los negocios que recoge la Nueva correspondencia de José $M$. Lopes presenta los rasgos que se han señalado para la mayoría de variedades especializadas o tecnolectos, esto es, son formas de comunicación entre expertos de una materia, se sirven de la gramática de la lengua común «matizada por ciertos usos que pueden destacar cualitativa o cuantitativamente», usan la impersonalidad y evitan la implicación afectiva, subordinan «lo estético y lo expresivo a lo objetivo a la eficacia comunicativa» $y$ son variedades que utilizan mayoritariamente el discurso escrito 5 .

4. Estas son las palabras que lo ratifican «y aun puede decirse, rigurosamente hablando, que solo hay tres lenguas comerciales: el francés, que propende cada día a ser el idioma universal; el inglés, no solo porque se habla en la Gran Bretaña y en los Estados Unidos de América, sino por el inmenso comercio que tienen estos dos grandes pueblos con todas las partes del mundo; el español por las extensas colonias que poseyó España en otro tiempo en ambas Américas, las cuales, si bien se han separado de su antigua metrópoli, han conservado su idioma y costumbres. Como lengua nativa, la castellana es la que se habla hoy en día en mayor extensión de territorio. El conocimiento de estos tres idiomas va a ser una necesidad, dentro de una época más o menos cercana, pues, con la abertura de los istmos de Suez y de Panamá, el Egipto por un lado y por otro las repúblicas de Nicaragua y Costa Rica y las grandes Antillas, llegarán a ser los dos mayores depósitos del universo» (Introducción, p. 7 y 8).

5. Ver Francisco Moreno Fernández, "Lenguas de especialidad y variación lingüística», en S. Barrueco, E. Hernández y L. Sierra (eds.), Lenguas para fines especificos (VI). Investigación y 
El lenguaje de los negocios exige, pues, conocer la forma de las cartas y escritos que para esta actividad se redactan, así como las diferencias que existen entre ellos, pues no es lo mismo componer una circular, un ofrecimiento de servicio o una operación comercial. Así, la obra de Lopes muestra distintos tipos de textos:

- 1) Algunos son breves y estereotipados y están caracterizados por la repetición de fórmulas de tratamiento ${ }^{6}$ (rogamos a Vds, se sirvan Vds de transmitirnos, considero útil decir a Vds), por la aparición de estructuras, sobre todo de inicio y despedida, invariables y fijas (tenemos el honor de anunciar, desde el día de la fecha, al pie de la presente, mis saludos de despedida con la expresión del respeto y consideración, permitanos Vd anunciarle, mientras se presenta una ocasión favorable para anudar nuestras relaciones), por el constante uso de gerundios (esperando sus órdenes definitivas, pudiendo disponer de suficientes capitales, rogándole que se sirva transmitirla [la confianza] a mi sucesor, refiriéndonos a nuestra antigua circular), por la abundante presencia de oraciones de relativo introducidas por $e l$ cual y cuyo (he fundado en esta una casa de comercio, cuyo objeto exclusivo será la comisión para todos los productos del mediodía de España e Islas Baleares; M. Galimard, empleado en mi casa hace doce años, en la cual tenía ya un interés; hemos interesado en nuestra casa al Sr Calas, cuyo zelo y adhesión nos han auxiliado poderosamente en todas nuestras operaciones mercantiles; solicitamos para nuestra nueva casa la misma confianza con que ha favorecido $V d$ la antigua, a la cual nos haremos acreedores por nuestros constantes esfuerzos), por la aparición de adverbios que acompañan a verbos y adjetivos para aclararlos y matizarlos (poderosamente, sumamente, ventajosamente, suficientemente, exclusivamente), por la utilización de verbos en presente, futuro e imperativo (sirvase, dígnese) o por el uso, en ocasiones accesorio, de adjetivos calificativos (tendríamos sumo placer, objetos más modernos, de mejor gusto y calidad, operarios tan inteligentes como expertos, se distinguirá [la fabricación] por su solidez y buen gusto, para recompensar el zelo e inteligencia de M. Galimard le asocio a mi comercio, siéndome notoria la perfecta honradez de su casa, doy a Vds las más expresivas gracias).

Estos escritos contienen, mayoritariamente, circulares, ofrecimientos de servicios y entradas en relaciones, esto es, su intención es informar, por lo que suelen usar los recursos y las formas de los textos descriptivos y expositivos. Sirvan como ejemplo la fundación de una casa de comercio o la circular dando aviso de un poder para firmar':

enseñanza, Alcalá de Henares, Universidad de Alcalá, 1999, p. 3-14.

6. Una enumeración detallada de los rasgos morfosintácticos del español escrito de los negocios se encuentra en José Joaquín Martínez Egido «El español escrito de los negocios: rasgos morfosintácticos», Frecuencia. Revista de didáctica de español lengua extranjera, 32, 2006, p. 48-50.

7. Las versiones francesas son:

Fondation d'une Maison de Commerce

Monsieur,

Nous avons l'honneur de porter à votre connaissance, qu'à dater d'aujourd'hui, nous avons fondé dans cette ville une maison de commerce sous la raison sociale Godino, Destrem et $C^{i e}$.

Nous nous occuperons essentiellement de la vente en commission de toute espèce de marchandises et des denrées coloniales.

En vous priant d'agréer l'offre de nos services, nous vous donnons l'assurance que nous regarderons vos intérêts comme étant les nôtres, et que vos ordres seront exactement exécutés.

Veuillez prendre note de nos signatures pour y ajouter foi, et nous croire en toute circonstance.

Vos respectueux serviteurs. 


\section{Fundación de una Casa de Comercio}

Muy señor nuestro,

Tenemos el honor de poner en su conocimiento que hemos fundado, en esta corte, desde el día de la fecha, una casa de comercio bajo la razón social Godino, Destrem y Ca.

Nos ocuparemos esencialmente de la venta en comisión de toda clase de mercancías y géneros ultramarinos.

Rogamos a Vd. que admita el ofrecimiento de nuestros servicios en la firme inteligencia de que miraremos sus intereses como los nuestros propios y sus órdenes serán exactamente ejecutadas.

Sírvase Vd. tomar nota de nuestras firmas para reconocerlas y considerarnos en esta como sus más atentos y SS.

\section{Dando aviso de un poder para firmar}

Muy señores nuestros,

Tenemos el honor de prevenirles que hemos dado nuestro poder general a madama Bonnet, madre. Al pie de la presente hallarán $\mathrm{Vds}$ su firma, rogándoles que la reconozcan como la nuestra propia.

Saludamos a Vds respetuosamente y quedamos sus atentos y SS.

- 2) Por su parte, los textos que recogen operaciones comerciales, además de informar sobre mercancías, precios y formas de pago, ordenan, solicitan y reclaman, por lo que son más directos; así, suelen prescindir o abreviar las fórmulas de salutación y despedida, usan un lenguaje claro y accesible, emplean una sintaxis simple y evitan el abuso de las formas de tratamiento. Es lo que ejemplifican los modelos de pedidos y de compras y ventas ${ }^{8}$.

\section{Prévenant d'une signature par procuration}

Monsieur,

Nous avons l'honneur de vous prévenir que nous avons donné à $\mathrm{M}^{\mathrm{me}}$ Bonnet, mère, notre procuration générale. Vous trouverez sa signature au bas de la présente, et nous vous prions d'y ajouter foi comme à la nôtre.

Veuillez agréer nos salutations respectueuses.

8. Las versiones en francés:

- Messieurs,

Pour satisfaire à une commande d'un de nos correspondants de Paris, nous vous prions de vouloir nous envoyer le plus tôt possible, par le roulage accéléré:

400 peaux de chevreau

200 do (dans le texte original unes fois "do" et d'autres "d") d'agneau, entièrement confectionnées

Les premières doivent être sèches et bien conditionnées pour le tannage: elles sont destinées à la fabrication de gants, et nous ne les accepterons pas si les petits chevreaux ont été sevrés.

Nous nous recommandons à vous pour la bonne expédition de notre demande, de laquelle vous voudrez bien nous envoyer facture.

Agréez nos salutions empressées.

- Monsieur,

Le prix moyen du suif a été hier de 107 fr. 50 c.; c'est une baisse de 50 centimes sur le précédent marché.

Profitant de cet avantage, j'ai l'honneur de vous annoncer que d'après vos instructions, j'ai acheté pour votre compte:

500 kil. suif en branche

300 do. stéarine

$\begin{array}{lll}\text { à } 82 \mathrm{fr} . & \text { les } 100 \mathrm{kil} . & 328 \mathrm{fr} . \\ \text { à } 185 \mathrm{fr} . & \text { do. } & 740 \mathrm{fr} . \\ \text { à } 96 \mathrm{fr} . & \text { do. } & 384 \mathrm{fr} . \\ & \text { Total } & 1.452 \mathrm{fr} .\end{array}$

200 do. oléine

Total

$1.452 \mathrm{fr}$.

Dont vous trouverez la facture ci-jointe, avec prière de vouloir m'en créditer et me transmettre de nouveaux ordres.

Recevez mes salutations empressées. 
Muy señores nuestros,

Para cumplir con un encargo de uno de nuestros corresponsales en París, rogamos

a Vds que nos envíen cuanto antes, por las galeras aceleradas,

400 pieles de cabrito

200 id. de borrego enteramente arregladas

Las primeras deben estar secas y preparadas para curtirlas; se destinan para la fabricación de guantes y no aceptaremos las que sean de cabritillas destetadas.

Recomendamos a Vds el buen desempeño de nuestro pedido, del que tendrán la bondad de remitirnos factura.

Esperando su contestación, quedamos de Vds atentos y SS.

Muy señores míos,

El precio medio del sebo ha estado ayer a 107 francos 50 cent., lo cual es una baja de 50 céntimos sobre el mercado de ayer.

Aprovechando, pues, esta circunstancia, tengo el honor de anunciar a Vd que, según sus intrucciones, he comprado por cuenta suya

$\begin{array}{lll}500 \text { kil de sebo en rama } & \text { a } 82 \mathrm{fr} . \text { los } 100 \text { kil. } & \text { fr. } 328 \\ 300 \text { kil. de estearina } & \text { a } 185 \text { fr. id. } & \text { fr. } 740 \\ 200 \text { kil. de oleica } & \text { a } 96 \text { fr. id. } & \text { fr. } 384\end{array}$

Total

fr. 1.452

Cuya factura hallará Vd adjunta, la cual se servirá Vd abonarme y transmitir órdenes a este SSS.

- 3) Los escritos de quejas, de justificación y amenazas judiciales, de solicitud de ampliaciones de plazo, de peticiones de dinero o que anuncian quiebras suelen ser más largos y presentan una mayor libertad estilística. Suelen tener más componentes expresivos, son más subjetivos, más artificiosos, con una sintaxis más elaborada, constantes apelaciones al interlocutor y verbos en primera persona de singular (suplico, siento, me veo precisado, agradezco, necesito); por ello, pueden incluir notas biográficas y la expresión de estados de ánimo, actitudes, sentimientos y deseos (era un simple dependiente de comercio en 1843, cuando mi buena conducta no solo me grangeó el aprecio de mis gefes sino también la confianza de varios fabricantes españoles y extranjeros [...]. Esto me obligó a hacer sacrificios de tal consideración, a fin de poder atender a mis compromisos, que mis pérdidas ascendieron en estos dos años a más de ciento sesenta mil francos; Tan aciago acontecimiento ha venido a destruir el fruto de veinte años de una vida honrada y laboriosa, lo cual me duele mucho menos que el daño involuntario que ocasiono a mis acreedores; Seis meses he estado luchando para conjurar esta catástrofe, que las últimas noticias han precipitado, pues mis intereses en la casa $R$. y Ca eran tan considerables que su quiebra me ha ocasionado una pérdida de 400.000 francos. Hágase Vd cargo de mi dolor y del terrible estado que me ha obligado a suspender mis propios pagos). Son buen ejemplo la contestación a un informe sobre un caso de locura o el anuncio de un naufragio?.

9. Las traducciones francesas dicen:

Réponse à une demande de renseignement.- Cas de folie

Messieurs,

Nous sommes honorés de votre lettre du 14 courant, par laquelle vous nous annoncez nous avoir crédités de fr. 4.836 pour les effets qu'elle renfermait; nous vous écrirons trés-prochainement à ce sujet.

Nous nous sommes occupés du renseignement que vous demandiez sous le même pli, touchant la maison Pedro Tasona de notre place. Cette personne a été déclarée aliénée en $18 \ldots$ et soumise á un traitement dans un établissement médical. Sa maison a été liquidée, par sentence juridique, et tous ses créanciers n'ont eu que de faibles á-compte, sans autre garantie, attendu que la loi espagnole ne considère pas le cas d'aliénation mentale comme pouvant donner lieu á une déclaration de faillite. Depuis deux ans, M. Tasona, guéri de son affection, au dire des médecins, s'est remis à la tête de ses affaires, ce dont personne ne peut l'empêcher, après s'être engagé de nouveau á s'acquitter envers ses anciens créanciers. Néanmoins, cette maison inspire ici trés- 


\section{Contestación a un informe.- Caso de locura}

Muy señores nuestros,

Hemos recibido su favorecida del 14 del corriente, en la que nos anuncian Vds habernos abonado fr. 4.836, por las libranzas que incluían Vds en la misma, y sobre lo cual contestaremos a Vds en breve.

Nos hemos ocupado del informe que nos pedían Vds en la misma, sobre la casa Pedro Tasona de esta plaza. Este sujeto fue declarado loco en $18 \ldots .$. y sometido a un tratamiento curativo en un establecimiento médico. Su casa fue liquidada por sentencia judicial y sus acreedores no cobraron más que unas cortas sumas a buena cuenta, sin ninguna otra garantía, porque la ley española no considera el caso de enagenación mental como susceptible de una quiebra. Dos años hace que el señor Tasona, curado de su enfermedad, según dijeron los facultativos, ha vuelto a dirigir sus negocios, cosa que nadie puede impedirle, después de haberse comprometido de nuevo a satisfacer sus antiguos acreedores. Estos sin embargo, la casa de Tasona inspira aquí muy poca confianza, porque la engenación mental está expuesta a recaídas y se halla siempre bajo el dominio del art. 10 del Código de Comercio espańol. Al pie de la presente transcribimos a Vds el texto de este artículo, que es, según creemos, el mejor dato que se pueda dar a su parroquiano de Vds tocante al Sr. Tasona, cuya moralidad no se halla comprometida por su pasada enfermedad.

Sin más por hoy y esperando sus órdenes, quedamos siempre sus atentos y SS.

\section{Anuncio de un naufragio}

Muy señores míos,

Siento infinito tener que darles una aciaga noticia.

Así como tuve el honor de anunciar a Vds en mi anterior de 17 del corriente, salimos de este puerto, con buen viento, el cual continuó hasta pasado el cabo de San Vicente, donde sobrevino de repente un viento bastante recio que se hizo luego grande fresco. Procuramos volver a esta, pero nos fue imposible. Viendo que el buque hacía mucha agua recurrimos a las bombas, pero, a pesar de todos nuestros esfuerzos, el agua iba ganando terreno. Como último recurso, hicimos rumbo hacia el puertecillo de Portugal más inmediato, que era el de Lagos, y estábamos a unas dos millas escasas

peu de confiance, attendu que l'aliénation mentale est sujette à récidiver et qu'elle reste sous la disposition de l'art. 10 du Code de commerce espagnol. Nous vous transcrivons plus bas le texte de cet article. C'est, nous le croyons, le meilleur renseignement à fournir à votre client, touchant M. Tasona, dont la moralité, du reste, n'est nullement compromise par son ancienne infirmité.

Veuillez agréer nos civilités,

Annonce d'un naufrage

- Messieurs,

Je suis extrêmement fâché des mauvaises nouvelles que j'ai à vous apprendre.

Nous partîmes de Cadix, comme j'eus l'honneur de vous l'annoncer par ma précédente, le 17 courant, avec un bon vent qui continua jusqu’après avoir passé le cap Saint-Vincent, lorsque tout à coup s'éleva un vent violent qui devint bientôt grand frais. Nous tâchâmes de regagner Cadix, mais ce fut en vain: comme le bâtiment faisait beaucoup d'eau, notre attention se dirigea sur les pompes, mais malgré tous nos efforts l'eau nous gagnait. Pour dernière ressource nous fimes route vers le premier petit port de Portugal; c'était Lagos. Nous n'en étions plus qu'à deux milles, quand un gros coup de mer fit chavirer le bâtiment, et en moins de cinq minutes il coula bas. Nous eûmes à peine le temps de mettre la chaloupe à l'eau pour nous sauver. Les pilotes portugais vinrent à notre secours, et c'est à eux que nous sommes redevables de la vie. Nous avons trouvé la plus grande hospitalité parmi les habitants du pays.

J'espère que, lorsque le temps sera calme, nous pourrons sauver une partie de la cargaison, car les débris du bâtiment se voient encore d'ici á marée basse. Soyez assuré que je ferai tout mon possible pour cela, et que je vous tiendrai au courant des travaux de sauvetage.

Agréez, messieurs, avec mes regrets de ce malheur, bien indépendant de ma volonté, l'assurance de mes profonds respects et de ma considération distinguée. 
de él, cuando una violenta ráfaga de viento hizo zozobrar el buque, teniendo apenas tiempo para echar el bote al agua y salvarnos en él. Los pilotos portugueses vinieron a auxiliarnos y a ellos somos deudores de la vida. Hemos hallado la mayor hospitalidad entre los habitantes de este país.

En cuanto se serene el tiempo, espero que podremos salvar una parte del cargamento, mayormente cuando los despojos del buque se ven desde aquí a la bajamar. Estén $\mathrm{Vds}$ persuadidos de que haré cuanto dependa de mí para lograrlo y pondré a Vds al corriente del resultado.

No pueden Vds figurarse cuanto siento este desastre independiente de mi voluntad. Reciban Vds la prueba de mi pesar y del respeto que les profesa este SSS.

- 4) Finalmente, los modelos de escrituras y poderes, tanto general como privado, reúnen rasgos más arcaizantes y conservadores: sintaxis con abundante subordinación, futuros de subjuntivo, impersonales con se, construcciones pasivas, perífrasis verbales, tecnicismos o formulismos (Si uno de los socios falleciere durante la existencia de la sociedad, esta será disuelta y liquidada; pero el socio que sobreviviere quedará obligado a dar cuenta a los herederos de su difunto consocio de todas las ganancias directas que resultaren de los negocios hechos durante la sociedad. La presente escritura privada hecha por duplicado obliga a los socios para todos los efectos de la ley, y cada uno conserva un ejemplar de la misma).

La utilidad de la Nueva correspondencia comercial, no obstante, no se limita a la exposición de los principales escritos del español de los negocios, sino que también revela las dificultades que entraña la traducción de determinadas fórmulas y estructuras; así, por ejemplo, José M. Lopes advierte a sus lectores franceses sobre la diferencia de las formas de tratamiento y las siglas en las dos lenguas o sobre el significado de algunos tecnicismos.

Les formules françaises sont très-claires et ne demandent aucune explication. Mais les espagnoles ne seraient pas compréhensibles, pour les étrangers, sans un mot d'éclaircissement.

La phrase Muy señor mío, dont la traduction littérale (très monsieur à moi) n'a pas de sens en français, est toujours la formule que l'on met en tête des lettres espagnoles non familières. Cette formule est sujette aux variations suivantes:

Lorsque c'est une seule personne qui écrit à une autre, on met tout simplement Muy señor mio.

Lorsqu'une seule personne écrit à deux ou à plusieurs autres, on doit mettre Muy señores míos.

Lorsque deux ou plusieurs personnes s'adressent à une seule, on met Muy señor nuestro.

Lorsque deux ou plusieurs personnes s'adressent à plusieurs autres, on met Muy señores nuestros.

Les Espagnols ont l'habitude de terminer leurs lettres par les sept lettres capitales suivantes:

S.S.S. qui signifient Su seguro servidor (son sûr serviteur), et

Q.S.M.B. qui signifient Que sus manos besa (qui baise ses mains*, c'est-à-dire les mains des personnes auxquelles est adressée la lettre) (p. 110-111)

* la traducción correcta sería "qui baise vos mains" ya que el tratamiento de cortesía francés es vous (segunda persona de plural) mientras que el español es de tercera persona (Usted, Ustedes).

La palabra roulage se traduce de varios modos en España, según los medios de transporte de cada provincia. Su verdadera traducción es acarreo terrestre, pero la sustituimos por la de mensagerías por ser vos más conocida (p. 423) 
La intencionalidad no es otra que la de de mostrar los principales rasgos del lenguaje de los negocios para no fallar en la redacción de ninguno de sus escritos, esto es, idénticos objetivos que muchos de los manuales ELE publicados en las últimas décadas. Sirva como ejemplo la Correspondencia comercial en español de J. García de Enterría ${ }^{10}$, quien reconoce en el prólogo que «la redacción comercial es aquella que tiene por objeto la comunicación en el mundo de los negocios y de la empresa. Las características que acabamos de enumerar [claridad, precisión, agilidad, persuasión y prudencia] tienen una gran importancia, ya que cuando no se cumplen en el escrito comercial están entorpeciendo la finalidad de éste; es decir, la buena marcha de los negocios». Es, por ello, necesaria la existencia de correspondencias que recojan los rasgos de este lenguaje y que los ejemplifiquen en diferentes documentos.

\section{El léxico comercial}

\section{a. El «Lenguage comercial»}

La Nueva correspondencia comercial, a pesar de reunir un amplio número de modelos de escritos comerciales, comienza con un vocabulario de tecnicismos -llamado «Lenguage comercial»- cuya incorporación su autor justifica así:

Antes de empezar la larga serie de cartas que forma el fondo de esta obra, creemos oportuno el dar algunas definiciones y explicaciones sobre ciertas palabras técnicas propias de la lengua comercial y económica. El comerciante, como todas las personas que ejercen profesiones liberales, necesita tener conocimientos especiales que no debe ignorar so pena de perjudicar a sus intereses (p. 23)

Estas palabras ponen de manifiesto que la intención de Lopes es la de enseñar la terminología del comercio y la economía, esto es, el «Lenguaje comercial» es un repertorio eminentemente terminológico cuya «pretensión consiste en dar unos conocimientos acerca de la realidad representada por ese vocabulario» $\mathrm{y}$ no en estudiar su vocabulario desde un punto de vista lingüístico ${ }^{11}$.

Por otro lado, la Nueva correspondencia está dirigida a comerciantes franceses y españoles que deseen no solo conocer el vocabulario especializado sino también traducirlo a ambas lenguas; por ello, Lopes recoge términos del discurso sectorial altamente especializado y términos menos especializados, didácticos o divulgativos, lo que explica que junto a fletamiento, agiotaje, corretaje, income tax, manosmuertas o derecho de puertas se encuentren bazar, crisis, fisco, gramo, lujo o producción, voces, estas últimas, de la lengua general que se convierten en tecnicismos en función de la situación comunicativa, el contexto y los participantes ${ }^{12}$, y que confirman la débil frontera que existe entre la lengua común y los lenguajes de especialidad.

10. Ver Josefa Gómez de Enterría, Correspondencia comercial en español, Madrid, SGEL, 1995, p. 10-13.

11. Cf. José-Álvaro Porto Dapena, Manual de técnica lexicográfica, Madrid, Arco/Libros, 2002, p. 49.

12. Cf. M. ${ }^{a}$ Teresa Cabré, La terminología. Representación y comunicación. Elementos para una teoría de base comunicativa y otros artículos, Barcelona, Universitat Pompeu Fabra, 1999, p. 123. 
El vocabulario del «Lenguaje comercial» contiene dos secciones: una con once entradas (comercio, valor, banco, banquero, bolsa, capital, crédito, baratocaro, cambio, interés y especulación), esenciales para realizar cualquier operación comercial, y otra formada por ciento ochenta y nueve que también necesitan ser explicadas para bien de los comerciantes.

Macroestructura. Las entradas están dispuestas por orden alfabético a partir de la lengua francesa, por lo que en la versión española no tienen orden alguno. Estas son de dos tipos: sencillas o formadas por un único término (agiotaje, cuenta, exportación, notario, cuarentena...) y complejas o formadas por varios sinónimos o equivalentes (bolsa o lonja; acopio, acopiamiento o estando; artículo o género; mostrador o factoria; abonar, acreditar; recibo, finiquito, carta de pago $o$ haciendo o rentas públicas). Además, es habitual -dado que es un repertorio que refiere a realidades objetivamente estructuradas ${ }^{13}$ - la presencia de subentradas, esto es, de entradas dentro del artículo lexicográfico que también son explicadas con detalle; por ejemplo, en el interior del artículo comercio se aclaran los significados de comercio interior, exterior y de mar; en acción se describen las acciones de industria, acciones nominales, acciones al portador; en balance se definen también balance de inventario, balance de salida y balance de entrada; en cuenta se especifican los significado de cuenta sumaria, dar cuenta, extender una cuenta, tener cuenta abierta, sentar en cuenta, en alza el de jugar al alza; en arqueo el de arquear; en moneda los de moneda de cobra, moneda de papel, moneda real o efectiva, monedage y monetización; y en cartera el de llevar su fortuna en la cartera).

La mayoría de estas entradas son, por tanto, sustantivos, si bien también se encuentra algún verbo (abonar, arquear, jugar al alza) y locuciones nominales (balance de comercio, apremio corporal, letra de cambio, carta de porte o uno por contra).

Por otra parte, el «Lenguaje comercial» contiene algunos artículos formados por una entrada o lema + una remisión interna, que puede llevar o bien a otra voz o bien a otra sección de la obra:

Acto de comercio (véanse los artículos del Código al fin de este tomo).

Dinero (véase Moneda).

Asociación (véase Sociedad).

Bolsa (descrito ya al principio).

Microestructura. Las informaciones que reúnen los artículos lexicográficos de este repertorio son heterogéneas y poco uniformes, de manera que hay artículos muy amplios y bien documentados y artículos muy breves y apenas comentados, como muestran los casos de agente de cambios, interés o adquisición, censo y velta:

Agente de cambios. Oficial ministerial, instituido en las ciudades en donde hay una bolsa de comercio, y encargado, como intermediario, de la negociación de los efectos públicos y particulares. Los agentes de cambios están encargados de redactar la cotización auténtica de los precios de los efectos públicos y de las materias de oro y plata. Sus atribuciones son las siguientes: $1^{\circ}$ negociar, como intermediarios de las

13. Cf. José-Álvaro Porto Dapena, op. cit., p. 48. 
partes, los efectos públicos y demás susceptibles de ser cotizados, todos los papeles comerciales y ventas de materias metálicas [...].

Interés. Es el alquiler que saca un propietario de su capital o el provecho que se obtiene de una suma de dinero enagenada a título de préstamo por un tiempo determinado o concedida por justicia a un acreedor contra su deudor atrasado en el pago. Este provecho que se saca del dinero varía según sea convencional o judicial. Cuando lo señala la justicia, el precio del dinero es siempre fijo y uniforme, tal como lo ha mandado la misma ley creando una tasa legal. Este interés es de 6 por 100 en materia de comercio y de 5 por 100 en materia civil. La facultad de prestar dinero a un interés libre está reconocida por el Código civil, art. 1905 y 1907, concebidos por estos términos: "Se permite estipular intereses por simple préstamos, sea de dinero, de géneros o de otras cosas mobiliarias" [...].

Adquisición (en francés acquêt) significa la cosa adquirida y también la acción de adquirir.

Censo (en francés redevance), obligación impuesta a una tierra o a cualquier propiedad.

Velta. Antigua medida, todavía usada en Francia, aunque sin carácter legal, que sirve para medir el contenido de los toneles. Equivale a 7,45 litros.

Tras la definición del término y su correspondencia francesa, aparecen explicaciones y observaciones de carácter enciclopédico muy variadas. Ahora bien, entre esas informaciones hay algunas que son útiles e interesantes desde el punto de vista lingüístico, a saber:

- incluye etimologías, como en comercio que procede "del latín commercium, voz compuesta de cum (con) y merces (mercancías)», o banco que viene del «italiano banco, que significa lo mismo en espańol»,

- separa acepciones o bien gráficamente con un guión largo, o bien léxicamente con la introducción de expresiones del tipo "dase también este nombre...», «se llama también...» o "es también...",

- distingue marcas de especialidad; así se dan tres definiciones para crédito, una en el lenguaje comercial, otra en derecho comercial y otra en contabilidad; dos definiciones para balance, una en el lenguaje comercial y otra en el marítimo; dos sentidos para estar al par, uno en el lenguaje comercial y otro en el bursátil; o dos acepciones de riqueza, una en el lenguaje vulgar y otra en el lenguaje económico,

- reconoce la utilización, como fuente, de otros repertorios lexicográficos (principalmente, del Diccionario de comercio y navegación ${ }^{14}$ ),

- ofrece explicaciones y matizaciones sobre el significado en francés de algunas voces («la palabra acquit se aplica, en francés, más particularmente a las letras de cambio, pagarés y demás efectos negociables. Su fórmula ordinaria es pour acquit, esto es, recibido, con la firma del portador al pie»),

- señala la sinonimia entre algunos términos (fletamiento: «este término, en francés affrétement o nolisement, es sinónimo de charte-partie, en español póliza de fletamiento o carta partida»; libranza: «sinónimo de letra de cambio»),

- informa sobre la introducción de préstamos de otras lenguas en el lenguaje comcercial, fundamentalmente anglicismos (bank-nota, bill, alien-bill, docks, drawback, warrant, yard) y germanismos (kreuzer, thaler, gulden, zollverein, zuber),

- $\quad$ y especifica las voces que cambian de significado según su número (provisión: «operación que consiste en juntar todo lo que es necersario a la subsistencia

14. Seguramente Lopes se refiere al Dictionnaire du commerce et des marchandises contenant tout ce qui concerne le commerce de terre et de mer dirigido por Gilbert-Urbain Guillaumin, publicado en París (Bourgoque et Martinet) en dos volúmenes entre 1837 y 1839. 
de una nación, ciudad, ejército, etc. Pero en plural, las provisiones designan principalmente los cereales y harinas destinadas para la alimentación de la ciudad»; fondo: «establecimiento industrial y comercial. En plural, fondos significan capital o suma más o menos destinada para cierto uso»).

Junto a la información lingüística, Lopes inserta otros pormenores y aclaraciones muy útiles para el comerciante: algunos fragmentos del Código de comercio para explicar algunas obligaciones y reglamentos así como de otras legislaciones (apremio corporal: «el apremio corporal es regido por las leyes del 7 de abril de 1832 y del 13 de diciembre de 1848, a las cuales puede recurrir el lector para enterarse por completo"), lecciones morales (por ejemplo, el autor afirma que no solo los bienes materiales conforman el capital, sino que también hay inmateriales como la salud, «un millonario enfermo daría gustoso la mitad de su fortuna por poseer la excelente salud y la robusta constitución de tal trabajador que se ve obligado a levantarse al amanecer para ir a su taller»), alusiones históricas (cambio: «en la infancia de las sociedades, el cambio se hacía en especie; luego después, para darle más facilidades, se imaginaron las monedas metálicas; en seguida se inventaron los billetes de banco [...]»), opiniones personales (define el acopio como «modo de especular algo tiránico») o comentarios de carácter enciclopédico, como las escalas de Levante (en donde enumera los principales puertos del Mediterráneo: Chipre, Constantinopla, El Cairo, Argel, Naxos...), la población de los diferentes continentes (Europa: 240 millones de habitantes, Asia: 560, África: 110, América: 70 y Oceanía: 30) o los instrumentos del trabajo y de la producción (facultades del hombre, el trabajo manual, las invenciones, el conjunto de los medios creados por la industria del hombre o del capital...).

Se trata, por tanto, de un compendio del vocabulario básico del comercio, compuesto para facilitar el desarrollo de su actividad a los mercantes franceses y españoles, pues no en vano «el comercio y la economía política tienen, como todas las ciencias, su lenguage particular; al enseñar esta lengua, se facilita su estudio» (p. 11).

\section{b. Las nomenclaturas de los términos de banco y comercio}

De la página 453 a la 604 de la Nueva correspondencia comercial se extienden dos repertorios alfabéticos que recogen "des termes de banque, commerce et comptabilité», uno francés-español y otro español-francés. Aunque aparentemente parece que se trata del mismo vocabulario ordenado desde lenguas diferentes, una mirada atenta sobre su contenido muestra que hay entre ellos diferencias notables.

Macroestructura. Las entradas están ordenadas alfabéticamente: en el primer repertorio a partir del francés y en el segundo del español. La primera nomenclatura contiene setecientos cincuenta y nueve artículos, y la segunda reúne novecientos cuarenta y ocho. Esta diferencia numérica se debe al distinto tratamiento que reciben los equivalentes en cada una de las partes: mientras que en la primera évaluer se traduce por «avaluar, evaluar, estimar», en la segunda cada una de estas voces tiene una entrada diferente, y lo mismo ocurre 
con encaissement, traducido por "cobro, cobranza, ingreso", o con déduire, por "deducir, desfalcar», equivalentes todos ellos que se lematizan en la versión espańola.

La mayoría de las entradas, tanto en una nomenclatura como en otra, son simples, es decir están formadas por una única entrada, si bien abundan también las subentradas formadas por unidades pluriverbales:

$\begin{array}{ll}\begin{array}{l}\text { bulletin, - de douane } \\ \text { conclure, - un marché, - un }\end{array} & \begin{array}{l}\text { boletín, - de aduana o cédula de } \\ \text { aduana } \\ \text { arrangement } \\ \text { céfalcation }\end{array} \\ \begin{array}{l}\text { trato, - un ajuste } \\ \text { dépenses }\end{array} & \text { Desfalco } \\ \text { échantillon, carte d'échantillons } & \text { Gastos } \\ \text { légaliser } & \text { muestra, mostrario } \\ \text { magasinage } & \text { Legalizar } \\ \text { numéro, - d'actions ou obligations, } & \text { almacenage } \\ \text { - remboursé } & \text { número, - de acciones u obligaciones, } \\ \text { profit, - profits et pertes } & - \text { reembolso } \\ & \text { provecho, ganancia, beneficio, - } \\ \text { ganancias y pérdidas }\end{array}$

Microestructura. Los artículos lexicográficos que recogen estas nomenclaturas son mucho más uniformes que los del vocabulario del «Lenguaje comercial» pues se limitan a indicar el equivalente o equivalentes en la otra lengua, y a advertir, con una remisión, si se encuentran en el «Lenguaje comercial»

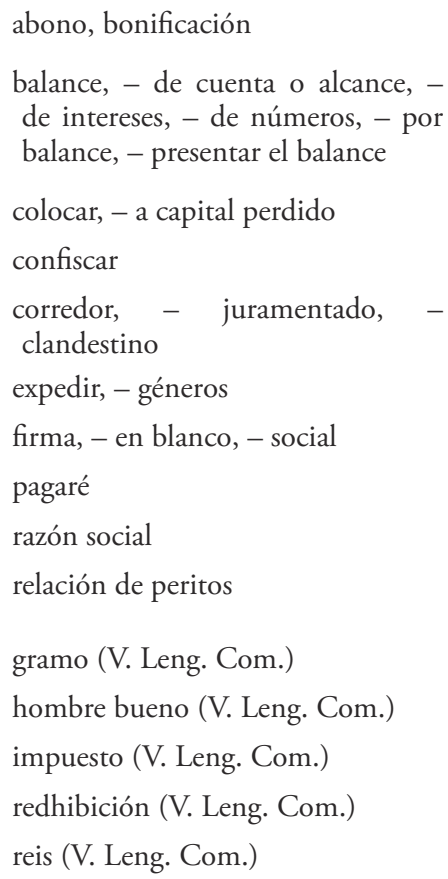

bonification

balance, - de compte, - d'intérêts, - de nombres, - pour balance, déposer le bilan

placer, -à fonds perdus

confisquer

courtier, - assermenté, - marron

espédier, - des marchandises

signature, - en blanc, - sociale

billet á ordre

raison sociale

expertise

gramme (V. Lang. Com.)

prud' homme (V. Lang. Com.)

impôt (V. Lang. Com.)

redhibition (V. Lang. Com.)

réis (V. Lang. Com.) 
Algunos de estos equivalentes, no obstante, se completan en ocasiones con informaciones lingüísticas de diverso tipo que podrían ser interesantes para los lectores y usuarios del manual. Así, se deslizan datos sobre la etimología de algunas voces, sobre su origen, sobre su significado, sobre sus acepciones o sobre sus diferentes usos entre los especialistas:

contestation, contestación (en sentido de disputar una cosa)

contrabande, contrabando, ilícito comercio

règlement, reglamento, ajuste, arreglo, cancelación (según las acepciones)

stock (mot anglais qui signifie ensemble de marchandises), Stock (palabra inglesa que significa conjunto de mercancías)

contra-mandar (dar contra-orden), contremander

Ahora bien, la sencillez de estos repertorios, impuesta por su finalidad práctica, no resuelve algunos problemas léxicos que surgen al consultarlos; así, hay ocasiones en que distintas voces presentan el mismo equivalente -sobre todo algunas palabras compuestas-, o equivalentes que varían en función de si se consulta la parte francés-español o la espańola-francesa

$\begin{array}{ll}\begin{array}{l}\text { déduire } \\ \text { défalquer }\end{array} & \begin{array}{l}\text { deducir, desfalcar } \\ \text { desfalcar }\end{array} \\ \begin{array}{l}\text { emmagasinage } \\ \text { magasinage }\end{array} & \begin{array}{l}\text { almacenage } \\ \text { almacenage }\end{array} \\ \begin{array}{l}\text { acquitter } \\ \text { payer }\end{array} & \text { pagar } \\ \text { pagar }\end{array}$


usurier, usurero

monopoleur, monopolista logrero, usurier, monopoleur

usurero, logrero, usurier

monopolista, monopoleur

Son unas nomenclaturas breves que, como el «Lenguaje comercial», tratan de ofrecer los equivalentes del léxico del comercio para, como afirma Lopes en la introducción, "corresponder un comerciante, en su lengua natal, con sus comitentes extrangeros, y estos, a su vez, le contestarán en su propio idioma, entendiéndose así todos recíprocamente sin necesidad de terceros» (p. 5).

\section{El léxico comercial de la Nueva correspondencia en el DRAE}

Los textos compuestos en esta centuria sobre lenguaje comercial y de los negocios son una buena fuente para conocer el vocabulario utilizado en las transacciones mercantiles, pues la mayoría de esos términos entraron en nuestros repertorios lexicográficos precisamente en esa época.

Los diccionarios decimonónicos, reflejo de los cambios y transformaciones ocurridos en la sociedad, muestran el incremento continuo de neologismos surgidos, como se ha demostrado en diversas ocasiones, de los acontecimientos que se produjeron en ese convulso periodo; así, se han señalado las innovaciones léxicas en el ámbito de la política, de la ciencia, de la vida social o de la indumentaria, lo que ha servido para afirmar que los cambios lingüísticos más importantes en esta época ocurrieron, precisamente, en el léxico ${ }^{15}$. El vocabulario del comercio no fue una excepción, y durante esta centuria continuaron incrementándose los neologismos relativos a la economía ${ }^{16}$.

El empleo y el aumento de voces nuevas de los negocios se comprueban no solo en la macroestructura de los diccionarios del español publicados en ese momento sino también en textos especializados como la Nueva correspondencia comercial. Así, Lopes emplea términos que entraron en el diccionario académico en la primera mitad del siglo XIX, como agio, agiotage, agiotista, cedente, inquilinato (1803), locación (1817), capitalizar, déficit (1822), poderdante (1832), justiprecio (1843), comanditario, comandita o cotización (1852), y también tecnicismos que la institución incorporaría ańos después, como monopolista, bolsin (1869), empaquetador (1884), librecambista, sinalagmático (1899), contracarta (1914), comanditar (1927), stock o contravalor (1985). Del mismo modo, en la Nueva correspondencia se documentan neologismos que aún no tienen cabida entre las páginas del diccionario de la Academia,

15. Voir Pedro Álvarez de Miranda, «El léxico español, desde el siglo XVIII hasta hoy», en R. Cano Aguilar (coord.), Historia de la lengua española, Barcelona, Ariel, 2004, p. 1037-1064.

16. En el siglo XVIII, como han demostrado Cecilio Garriga Escribano («Notas al léxico económico del siglo XVIII", en A. Alonso González et al. (eds.), Actas del III Congreso Internacional de Historia de la lengua española, Madrid, Arco/Libros, 1996, vol. II, p. 1279-1288) y Josefa Gómez de Enterría (Voces de la economía y el comercio en el español del siglo XVIII, Alcalá de Henares, Universidad de Alcalá, 1996) se produce la primera gran entrada de términos de la economía y el comercio. 
como agiotar, letrita, conmitente, velta o los préstamos docks, drawback, kreuzer, warrant, whatt, zollverein, zuber e income tax; enumeración que constata la importancia que, junto a los compuestos surgidos de los procedimientos morfológicos de formación de palabras en español, tuvieron en la introducción de préstamos el francés y, sobre todo, el inglés.

Pero la riqueza léxica de la Nueva correspondencia no termina aquí: J. M. Lopes incluye en las páginas finales un "Dictionnaire des marchandises» y un "Diccionario de mercancías», esto es, una completa lista de los artículos con los que se comerciaba en el siglo XIX. De la información de estos catálogos se descubre, por ejemplo, que consumían aceite de oliva, de colza, de hígado de bacalao, de ballena y de coco, alcaparrones, azúcar florete, moreno, blanco, en pilón, negro, de plomo o candi, canela de China, habas caballinas, habas de laguna, té verde, té negro o té perla, o que se vestían con babuchas, basquiñas, batista de Holanda, canesú, carrilleras, encajes, fieltros, fustán, gasas, guantes de ante, guantes de cabritilla, lana mestiza, lana lavada a plomo, lana de vicuña o lana pelada, ligas, mantones, miriñaque, organdí, pieles de leopardo, pieles de gacela, pieles de chinchilla o tirantes de goma elástica.

De nuevo algunas de estas voces fueron introducidas en la primera mitad del siglo, otras son neologismos - de forma o de contenido- de la Nueva correspondencia y otras aún no han llegado a los repertorios de la Real Academia:

\begin{tabular}{|l|c|}
\hline & $\begin{array}{c}\text { Primera aparición en el } \\
\text { DRAE }\end{array}$ \\
\hline $\begin{array}{l}\text { piocha, alcali, tasugo, salchichería, flloseda, hidrómetro, indiana, } \\
\text { mitón, rallador, sopera, destornillador, sacacorchos }\end{array}$ & 1803 \\
\hline areómetro, bismuto, malina, similor, tapioca, carrillera & 1817 \\
\hline Palastro & 1822 \\
\hline varillaje, bayetón & 1832 \\
\hline enjuagatorio, jeringa, calcetín & 1837 \\
\hline cachucha, trombón, babucha & 1843 \\
\hline acetato, alepin, tarjetero & 1852 \\
\hline $\begin{array}{l}\text { alcalimetro, bocoy, chichonera, cornalina, molibdeno, } \\
\text { plombagina, fosforera, tul, vagón }\end{array}$ & 1869 \\
\hline $\begin{array}{l}\text { ambarina, madapolán, catecú, baticola, daguerrotipo, metrónomo, } \\
\text { pantufla, ensaladera, estearina, tartán, tiralíneas, brisera, arseniato, } \\
\text { algodón (es la primera vez que la Academia da la definición del } \\
\text { tejido) }\end{array}$ & 1884 \\
\hline arsenito, lustrina, paladio, botito & 1899 \\
\hline \begin{tabular}{l} 
mantequillera, castorina, organdi, azucarera \\
\hline $\begin{array}{l}\text { alquifol, fagote, berta, indigotina, cachemira, calicó, rompenueces, } \\
\text { municionera (solo en las ediciones de 1927 y de 1950), popelina }\end{array}$
\end{tabular} & 1925 \\
\hline
\end{tabular}




\begin{tabular}{|l|c|}
\hline bayarte, cayeput, calzoncillo & 1936 \\
\hline Guardabrisas & 1970 \\
\hline $\begin{array}{l}\text { arcansón, molletón, betilla, bocasi, clisopompo, sacócola, cutil, } \\
\text { drill, limpiaoidos, fután, galipodio, madrenaga, rascalenguas, } \\
\text { enjuagador, ruanería, esquita, cambaya, pruebalicores }\end{array}$ & --- \\
\hline
\end{tabular}

\section{A MODO DE CONCLUSIÓN}

El análisis de la Nueva correspondencia comercial de José M. Lopes ha evidenciado la necesidad de completar la descripción de la historia de nuestra lengua con textos no incluidos tradicionalmente en los corpus de referencia. Esta obra, compuesta en un periodo de grandes transformaciones sociales y económicas y que recoge una gran variedad de escritos utilizados en las transacciones comerciales, permite caracterizar el español de los negocios del siglo XIX e invita a reflexionar sobre diversos aspectos: a) sobre determinados usos lingüísticos, pues la redacción de una circular, un ofrecimiento o una queja exige el dominio de diferentes recursos lingüísticos; b) sobre la entrada y utilización de neologismos, porque, como ha quedado demostrado, la Nueva correspondencia constituye una buena fuente para conocer la terminología que se empleaba en los negocios; así mismo, la información léxica que contiene puede resultar muy útil para trazar la historia del léxico español, pues muchas de las voces aparecidas no se encontraban en 1864 en el diccionario de la Real Academia Española; y c) sobre la importancia y las consecuencias de los textos traducidos, ya que no debe obviarse el alcance de algunos textos franceses e ingleses decimonónicos en la configuración de los rasgos lingüísticos que se han señalado para el español de los negocios.

Por otro lado, y en un momento en el que proliferan los manuales de español LE para los negocios, la Nueva correspondencia constituye un claro antecedente de los libros de texto que tratan de "proporcionar una serie de pautas para alcanzar el dominio de la redacción, a partir de un amplio abanico de textos comerciales y profesionales» (J. Gómez de Enterría, 1995: 5). Poco han variado, pues, la intencionalidad y el contenido. 


\section{Referencias bibliográficas}

Manuel Alvar Ezquerra, «Vocabularios específicos y vocabulario general», en A. Escobar (ed.), Lingüistica y Educación. Actas del IV Congreso de ALFAL, Lima, Universidad Nacional Mayor de San Marcos, 1978, p. 164-177.

Pedro Álvarez de Miranda, "El léxico español, desde el siglo XVIII hasta hoy», en R. Cano Aguilar (coord.), Historia de la lengua española, Barcelona, Ariel, 2004, p. 1037-1064.

M. ${ }^{a}$ Dolores Azorín Fernández y M. a Isabel Santamaría, «Los lenguajes de especialidad en los diccionarios del español de la primera mitad del siglo XIX», en J. Brumme (ed.), La historia dels llenguatges iberoromanics d'especialitat (segles XVII-XIX); solucions per al present, Barcelona, Universitat Pompeu Fabra, 1998, p. 359-378.

M. ${ }^{a}$ Teresa Cabré, La terminología: teoría, metodología, aplicaciones, Barcelona, Ediciones Antártida, 1993, 529 p.

M. ${ }^{a}$ Teresa Cabré, La terminología. Representación y comunicación. Elementos para una teoría de base comunicativa y otros artículos, Barcelona, Universitat Pompeu Fabra, 1999, $369 \mathrm{p}$.

Joan Corominas y José Antonio Pascual, Diccionario crítico etimológico castellano e hispánico, Madrid, Gredos, 1987-1991, 6 vols.

Ceciclio Garriga Escribano, "Notas al léxico económico del siglo XVIII», en A. Alonso González et al. (eds.), Actas del III Congreso Internacional de Historia de la lengua española, Madrid, Arco/Libros, 1996, vol. II, p. 1279-1288.

Josefa Gómez de Enterría, Correspondencia comercial en español, Madrid, SGEL, 1990, $133 \mathrm{p}$.

Josefa Gómez de Enterría, Voces de la economía y el comercio en el español del siglo XVIII, Alcalá de Henares, Universidad de Alcalá, 1996, 260 p.

Andreu Van Hooft (dir.), Textos y discursos de especialidad: El español de los negocios, Ámsterdam/New York, Rodopi, 2004, 130 p.

José M. ${ }^{a}$ López Piñero (ed.), La ciencia en la España del siglo XIX, Madrid, Marcial Pons, 1992, $240 \mathrm{p}$.

Francisco Moreno Fernández, «Lenguas de especialidad y variación lingüística», en S. Barrueco, E. Hernández y L. Sierra (eds.), Lenguas para fines especificos (VI). Investigación y enseñanza, Alcalá de Henares, Universidad de Alcalá, 1999, p. 3-14.

José Joaquín Martínez Egido, «El español escrito de los negocios: rasgos morfosintácticos», Frecuencia. Revista de didáctica de español lengua extranjera, 32, 2006, p. 48-50.

José-Álvaro Porto Dapena, Manual de técnica lexicográfica, Madrid, Arco/Libros, 2002, $367 \mathrm{p}$. 